\title{
Steady-State Thermal-Hydraulic Analysis of TRIGA Research Reactor
}

\author{
Mohammad Mizanur Rahman 1*, Mohammad Abdur R. Akond2, \\ Mohammad Khairul Basher ${ }^{2}$, Md. Quamrul Huda1 \\ ${ }^{1}$ Nuclear Energy Division, Energy Institute, Atomic Energy Research Establishment, Savar, Dhaka, Bangladesh \\ ${ }^{2}$ Renewable Energy Division, Energy Institute, Atomic Energy Research Establishment, Savar, Dhaka, Bangladesh \\ Email: ${ }^{*}$ dr.mizanrbd@gmail.com
}

Received 2 January 2014; revised 11 February 2014; accepted 6 March 2014

Copyright (C) 2014 by authors and Scientific Research Publishing Inc.

This work is licensed under the Creative Commons Attribution International License (CC BY). http://creativecommons.org/licenses/by/4.0/

(c) (i) Open Access

\section{Abstract}

The COOLOD-N2 and PARET computer codes were used for a steady-state thermal hydraulic and safety analysis of the 3 MW TRIGA Mark-II research reactor located at Atomic Energy Research Establishment (AERE), Savar, Dhaka, Bangladesh. The objective of the present study is to ensure that all important safety related thermal hydraulic parameters uphold margins far below the safety limits by steady-state calculations at full power. We, therefore, have calculated the hot channel fuel centreline temperature, fuel surface temperature, cladding surface temperature, the departure from nucleate boiling (DNB) heat flux and DNB ratio, axial fuel centreline temperature and compared. The comparison indicates that the calculated values are in satisfactory agreement between the codes. The data obtained in this investigation are largely far to compromise safety of the reactor. The results can also be used to upgrade the current core configuration of the TRIGA reactor.

\section{Keywords}

COOLOD-N2, PARET, TRIGA Mark-II, DNB, Safety

\section{Introduction}

The 3 MW TRIGA Mark-II research reactor was commissioned in late 1986 at Savar near Dhaka, Bangladesh. The reactor is a light water cooled with a graphite reflector. It was designed for steady state and square wave operation up to a power level of $3 \mathrm{MW}$ (th) and for pulsing operation with a maximum pulse power of $852 \mathrm{MW}$. The reactor is designed for multipurpose uses, such as training, education, radioisotope production, and various $\mathrm{R} \& \mathrm{D}$ activities in neutron activation analysis, neutron scattering and neutron radiography [1]. The reactor core is

\footnotetext{
"Corresponding author.
} 
located near the bottom of the reactor tank. The reactor tank is made of aluminum alloy of type 6061-T6 which is installed inside the reactor shield structure. The length and diameter of the tank is $8.23 \mathrm{~m}$ and $1.98 \mathrm{~m}$, respectively. The tank is filled up with 24,865 liters of demineralized water. The reactor core consists of 100 fuel elements including 5 fuel follower control rods and 2 instrumented fuel elements. These fuel elements are arranged in a concentric hexagonal array within the core shroud [2]. The fuel is a solid, homogeneous mixture of Er-U-ZrH alloy containing $20 \%$ by weight of uranium enriched to $19.7 \%{ }^{235} \mathrm{U}$, and about $0.47 \%$ by weight of erbium. The cutaway view of TRIGA reactor is shown in Figure 1.

The thermal and hydrodynamic objective of the design is to safely remove the heat generated in the fuel without producing excessive fuel temperatures or stream void formations and without closely approaching the hydrodynamic critical heat flux under steady-state operating conditions.

The present study represents a steady-state thermo-hydraulic and safety analysis of TRIGA Mark-II research reactor. The main objective of the study is to ensure that all important thermal hydraulic parameters uphold margins far below the safety limits. We, therefore, have calculated fuel centreline temperature, cladding temperature, coolant temperature, the departure from nucleate boiling (DNB) heat flux and DNB ratio. Calculations were performed with the thermal hydraulic codes COOLOD-N2 and PARET based on the axial power factor distributions obtained by 3-D Monte Carlo code MCNP4B2 with the updated nuclear data libraries. All of these calculations were made with water inlet temperature of $45.6^{\circ} \mathrm{C}$ and inlet pressure of $163.8 \mathrm{kPa}$ that corresponds to the static pressure of water from the top to bottom of reactor channels. The present study will be used to determine the safety margins of the current core configuration. This investigation will also provide a basis for upgrading the current core configuration through benchmarking the available TRIGA experimental and operational data for steady-state operations.

\section{Brief Description of Codes and Methodology}

A steady-state thermal hydraulic analysis was performed using the power distributions obtained from 3-D Monte Carlo code MCNP4B2 to determine the mass flow rate of coolant during steady-state operating condition under natural condition of coolant flow mode. A mass flow rate for a downward forced coolant flow is equivalent to $3500 \mathrm{gal} / \mathrm{min}$ was adopted from the final safety analysis report [3]. The axial power distribution of different fuel elements within the TRIGA core obtained by MCNP is represent in Figure 2. The parameters required for the thermal hydraulic analysis are tabulated in Table 1 [2] [4].

The COOLOD-N2 [5] code provides a capability for the analyses of the steady-state thermal hydraulics of research reactors. This code is revised version of the COOLOD-N code, and is applicable not only for research reactors in which plate-type fuel is adopted, but also for research reactors in which rod-type fuel is adopted. The COOLOD-N2 code can calculate fuel temperatures under both forced convection cooling mode and natural convection cooling mode as well as COOLOD-N code. In the COOLOD-N2 code, a "Heat Transfer Package" [6] is used for calculating heat transfer coefficient, DNB heat flux. In case of rod type fuel, DNB heat flux is calculated by both the "Heat Transfer Package" and Lund DNB heat flux correlation [7] which is popular for TRIGA type fuels.

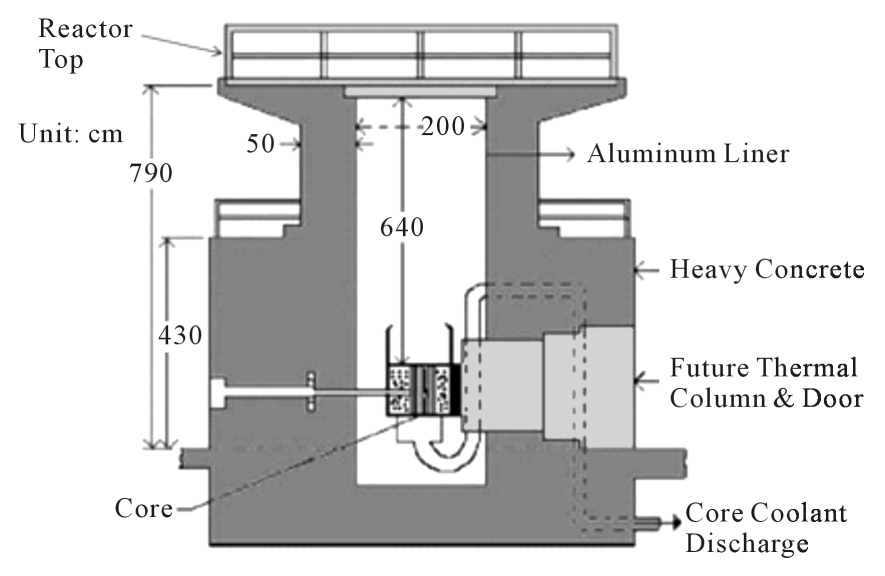

Figure 1. Cutaway view of TRIGA reactor. 


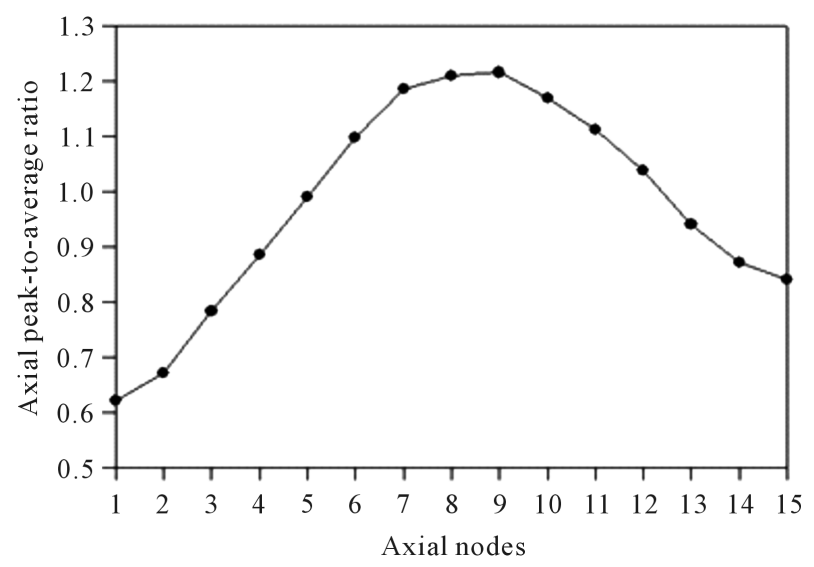

Figure 2. Axial power distribution of different fuel elements within the TRIGA core.

Table 1. Principal design conditions of TRIGA Mark-II research reactor.

\begin{tabular}{|c|c|}
\hline Geometric/Hydraulic Description & Value \\
\hline Fuel element & 20 w/o U-ZrH, 19.7\% enriched \\
\hline Total number of fuel in the core & 100 \\
\hline Operating power (MW) & 3 \\
\hline Cladding & Stainless steel $304 \mathrm{~L}$ \\
\hline Reflector & Graphite \\
\hline Inlet temperature $\left({ }^{\circ} \mathrm{C}\right)$ & 40.6 \\
\hline Active fuel length (m) & 0.381 \\
\hline Fuel radius (m) & 0.0182245 \\
\hline Clad outer radius (m) & 0.0187706 \\
\hline Coolant channel height (m) & 0.70307 \\
\hline Pool depth (m) & 7.10307 \\
\hline Core average heat flux $\left(\mathrm{W} / \mathrm{m}^{2}\right)$ & $6.72015 \times 10^{5}$ \\
\hline Hot rod factor & 1.7 \\
\hline Flow area $\left(\mathrm{m}^{2}\right)$ & $5.332635 \times 10^{-4}$ \\
\hline Hydraulic diameter (m) & 0.0180594 \\
\hline Pressure $(\mathrm{kPa})$ & 163.8 \\
\hline Friction loss coefficient & 0.07 \\
\hline Pressure loss coefficient & 1.81 (inlet); 2.12 (outlet) \\
\hline Pitch (m) & 0.045716 \\
\hline \multicolumn{2}{|l|}{ Mass flow rate $\left(\mathrm{kg} / \mathrm{m}^{2} \mathrm{~s}\right)$} \\
\hline \multirow{4}{*}{ (a) Natural convection mode } & 145.2 (at $500 \mathrm{~kW}$ ) \\
\hline & 120.55 (at $300 \mathrm{~kW}$ ) \\
\hline & 81.03 (at $100 \mathrm{~kW}$ ) \\
\hline & 6.63 (at $100 \mathrm{~W}$ ) \\
\hline (b) Forced convection mode & $3.2089 \times 10^{3}$ \\
\hline \multicolumn{2}{|l|}{ Coolant velocity (m/sec) } \\
\hline (a) Natural convection mode & 0.3048 \\
\hline (b) Forced flow & 2.8758 \\
\hline
\end{tabular}


To study the steady state thermo-hydraulic behavior of TRIGA research reactor, Argone National laboratory's PARET code was used. The PARET code was selected because of general applicability, its simplicity of coding, and rapid execution. PARET is designed for use in predicting the course and consequences of nondestructive reactivity accidents in small reactor cores [8]. It is a coupled neutronic-hydrodynamic heat transfer code employing point kinetics, one-dimensional hydrodynamics, and one-dimensional heat transfer.

\section{Results and Discussion}

\subsection{Steady-State Thermal Hydraulic Analysis}

The steady-state thermal hydraulic calculations were performed based on COOLOD-N2 and PARET models of the 3 MW TRIGA Mark-II research reactor located at AERE, Savar, Dhaka, Bangladesh and the results were compared. The power distribution from MCNP4B2 of the hottest fuel element of the core was calculated using the 3-D Monte Carlo code MCNP4B2 and the average values were adopted in each axial node. The power distribution profile of the hottest element at 3 MW integral core power calculated by MCNP4B2 is mapped in Figure 2. In the steady-state analysis using PARET, the steady-state parameters were found to be not sensitive to the temperature reactivity coefficients and were set to zero. The mass flow rate needed for input to PARET was generated using NCTRIGA code.

The design inlet temperature of $40.6^{\circ} \mathrm{C}$ corresponds to the heat exchanger operating on the hottest day anticipated at the reactor site. Because surface boiling is predicted for the hottest elements, the inlet temperature has virtually no effect on the maximum fuel temperature. Since the reactor pool is open at the top, the possibility exists for accidental blocking of one or more openings in the top grid plate with debris or a tool dropped from the reactor hall. However, the region below the grid plates is almost completely open to lateral cross-flow so that the blocked element (or elements) will suffer essentially no cooling loss.

The comparison of the fuel centerline temperature predicted by COOLOD-N2 and PARET codes are presented in Figure 3. It can be seen from this figure that the fuel centerline temperature as a function of reactor power was found to be satisfactory agreement between the codes COOLOD-N2 and PARET. The maximum fuel centreline temperature at $3 \mathrm{MW}$ power was predicted to be $775.27^{\circ} \mathrm{C}$ and $797.32^{\circ} \mathrm{C}$ for COOLOD-N2 and PARET codes, respectively. The observed temperatures for the fuel centerline is far below the fuel swelling temperature limit of $950^{\circ} \mathrm{C}$ made by General Atomic [3] design limit was conservatively chosen to avoid excessive swelling and growth.

\subsubsection{DNB Heat Flux and DNB Ratio}

The point at which the heat transfer from a fuel rod rapidly decreases due to the insulating effect of a steam blanket that forms on the rod surface when the temperature continues to increase is called DNB (departure from nucleate boiling). This generates a rapid increase in clad surface temperature. In sub-cooled boiling, the DNB heat flux is a function of the coolant velocity, the degree of sub-cooling, and the pressure. In case of rod-type fuel, COOLOD-N2 calculates DNB heat flux by both the "Heat Transfer package" and Lund DNB heat flux correlation which is popular for TRIGA reactor. In the case of PARET code, the Bernath correlation was selected as it gives the minimum value [8] and according to the suggestions made by GA [3]. The heat flux profile calculated by COOLOD-N2 and PARET along the hot channel is shown in Figure 4. For both of the codes the peak heat flux occurs at the axial center of the fuel elements. Only a small amount of local, subcooled nucleate boiling is predicted for the hottest elements over a length of $0.19 \mathrm{~m}$ at the axial center. Good agreement of heat flux is observed between COOLOD-N2 and PARET codes until the axial length of $0.15 \mathrm{~m}$. But over the axial length of $0.15 \mathrm{~m}$ the COOLOD-N2 code over estimates the heat flux than that of the PARET code which can be explained by the difference between correlations implanted in each code.

The DNB ratio (DNBR), which is defined as the ratio of the critical heat flux to the heat flux achieved in the core. For PWRs the resulting thermal design limit is expressed in terms of the minimum DNBR [9]. The DNBR is evaluated on the basis of hot channel axial distribution of peaking factors. The hot channel axial DNBR distribution evaluated by COOLOD-N2 and PARET codes at $3 \mathrm{MW}$ power is depicted in Figure 5. In case of COOLOD-N2 code, Over the length $0.381 \mathrm{~m}$ of the hottest channel the DNBR varies, starting from 4.52 - 5.49 with a minimum of 3.17 around the axial center of the fuel element. Whereas, in case of PARET code, the minimum DNBR is observed to be 2.7851 starting from 3.8951 to 5.4031 . The COOLOD-N2 code slightly over estimates the minimum DNBR from the safety limit on this parameter. 


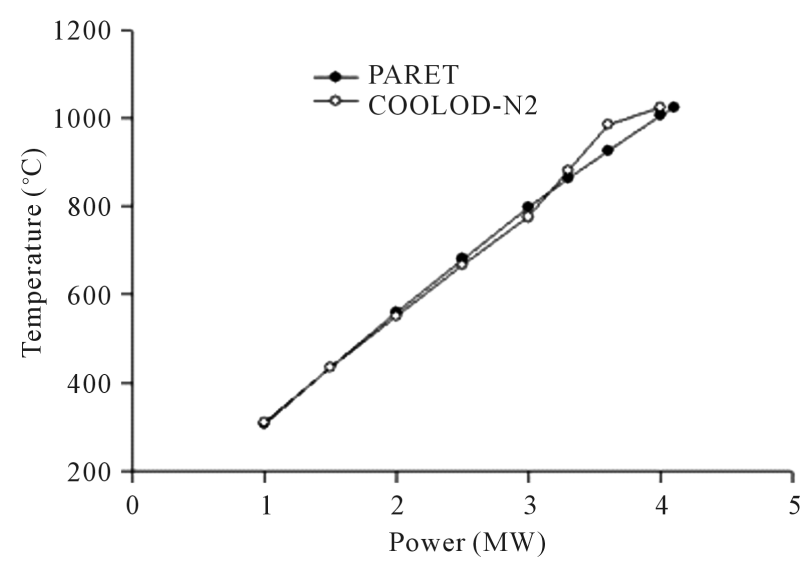

Figure 3. Comparison of the fuel centerline temperature predicted by COOLOD-N2 and PARET codes.

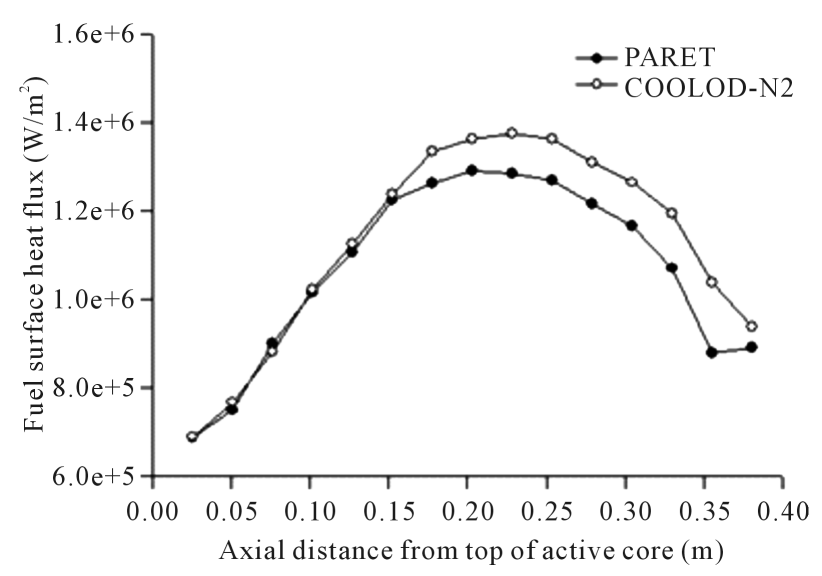

Figure 4. Heat flux profile calculated by COOLOD-N2 and PARET along the hot channel.

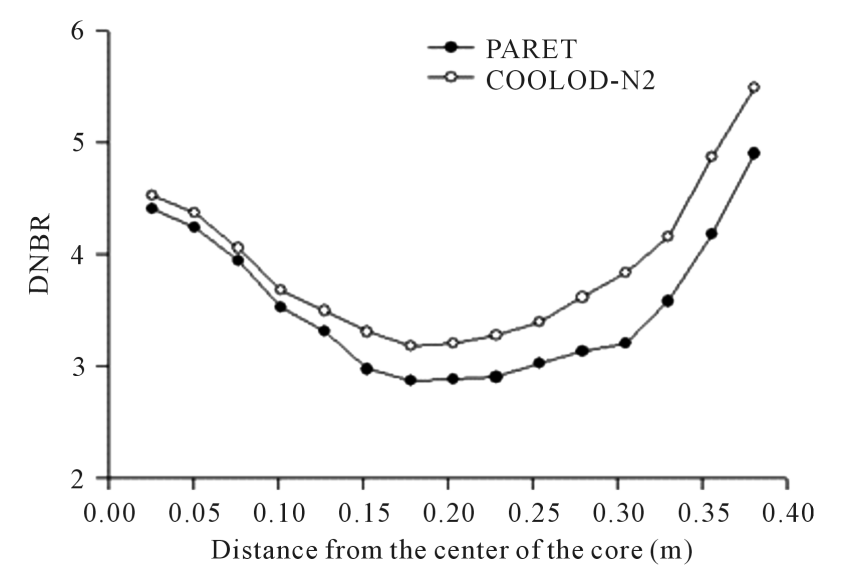

Figure 5. Hot channel axial DNBR distribution evaluated by COOLOD-N2 and PARET codes at $3 \mathrm{MW}$ power.

\subsubsection{Axial Temperature Profiles}

The comparison of axial temperature profiles of the TRIGA hot channel between COOLOD-N2 and PARET codes at $3 \mathrm{MW}$ power are presented in Figure 6. It can be seen from the figure. That the maximum temperature of fuel centerline, fuel surface, clad surface and bulk coolant is observed at the center of the active core. The fuel 


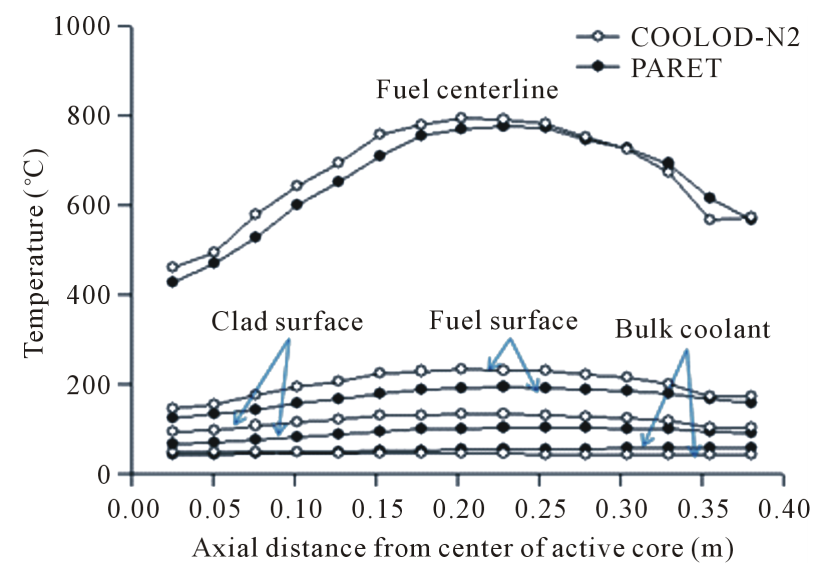

Figure 6. Comparison of axial temperature profiles of the TRIGA hot channel between COOLOD-N2 and PARET codes at 3 MW power.

surface temperature, clad surface temperature and bulk coolant temperature is found to be far below the fuel centerline temperature. In both of the codes, the axial temperature distribution is observed to be higher around the center of the fuel element. Good agreement of temperature distribution between two codes with minor discrepancies is observed which might be due to the difference between correlations used in each code. It can be seen that the largest temperature increases occur through the fuel and through the fuel cladding interface. The maximum fuel centreline temperature is found to be well below the safety limits mentioned in the FSAR.

\section{Conclusion}

The thermal hydraulic and safety analysis of the 3 MW TRIGA Mark-II research reactor at AERE, Savar, Dhaka, Bangladesh have been evaluated with the computer codes COOLOD-N2 and PARET. The calculation results of COOLOD-N2 were compared with that of PARET and found to be quite consistent. The results shows that the thermal hydraulic models through the hot channel fuel centreline temperature in steady-state condition are validated within error margins. In steady-state operation power, the analysis also ensures that all thermal hydraulic safety related parameters are within the thermal design limits. It is, therefore, concluded that the 3 MW TRIGA Mark-II research reactor at AERE, Savar, Dhaka, Bangladesh is safe to operate under its normal operating power. The results obtained in this investigation can also be used for upgrading the current core configuration of the TRIGA reactor.

\section{References}

[1] Hossain, S.M., Zulquarnain, M.A., Kamal, I. and Islam, M.N. (2011) Current Status and Perspectives of Nuclear Reactor Based Research in Bangladesh. IAEA, Vienna, 7-14.

[2] Huda, M.Q., Bhuiyan, S.I., Chakroborty, T.K., Sarker, M.M. and Mondal, M.A.W. (2001) Thermal Hydraulic Analysis of the 3 MW TRIGA MARK-II Research Reactor. Nuclear Technology, 135, 51-66.

[3] FSAR (2006) Final Safety Analysis Report for 3 MW TRIGA MARK-II Research Reactor at AERE, Savar, Dhaka, Bangladesh. BAEC, Dhaka.

[4] Rahman, M.M., Hussain, M.S., Imtiaz, M.A. and Huda, M.Q. (2012) Computational Analysis of Thermo-Hydraulic Behaviour of TRIGA Research Reactor. Annals of Nuclear Energy, 49, 48-56. http://dx.doi.org/10.1016/j.anucene.2012.05.034

[5] Kaminaga, M. (1994) COOLOD-N2: A Computer Code, for the Analyses of Steady-State Thermal Hydraulics in Research Reactors, JAERI Report. Japan Atomic Energy Research Institute, Tokai-mura, Ibaraki.

[6] Sudo, Y., Ikawa, H. and Kaminaga, M. (1985) Development of Heat Transfer Package for Core Thermal Hydraulics Design and Analysis of Upgradded JRR-3. Proceedings of the International Meeting of Reduced Enrichment for Research and Test Reactors, Petten, 14-16 October 1985, 363-372.

[7] General Atomics (1979) 10 MW TRIGA-LEU Fuel and Reactor Design Description. General Atomics, San Diego.

[8] Obenchain, C.F. (1969) PARET-A Program for the Analysis of Reactor Transients. IDO-17282, Idaho Atomic Energy 
Division, USAEC, Idaho.

[9] Boulaich, Y., Nacir, B., El Bardouni, T., Zoubair, M., El Bakkari, B., Merroun, O., El Younoussi, C., Htel, A., Boukhal, H. and Chakir, E. (2011) Steady-State Thermal Hydraulic Analysis of the Moroccan TRIGA Mark-II Reactor. Nuclear Engineering and Design, 241, 270-273. http://dx.doi.org/10.1016/j.nucengdes.2010.10.033 